\title{
A Case of the Traumatic Common Carotid Artery Injury Treated by Autograft
}

\author{
Min Hyuck Kang ${ }^{1}$, Young Kang ${ }^{1}$ (D) Hahn Jin Jung ${ }^{1}$, Lee Chan Jang ${ }^{2}$, and Dong Wook Lee ${ }^{1}$ (D) \\ ${ }^{1}$ Departments of Otorhinolaryngology-Head and Neck Surgery, ${ }^{2}$ Surgery, Chungbuk National University College of Medicine, \\ Cheongju, Korea
}

\section{응급 자가혈관 이식으로 치료한 외상성 총경동맥 손상 1예}

강민혁 ${ }^{1} \cdot$ 강 영 $^{1} \cdot$ 정한진 $^{1} \cdot$ 장이찬 $^{2} \cdot$ 이동욱 ${ }^{1}$

충북대학교 의과대학 이비인후과학교실, ${ }^{1}$ 외과학교실 ${ }^{2}$

\author{
Received June 25, 2020 \\ Revised July 30, 2020 \\ Accepted July 31,2020 \\ Address for correspondence \\ Dong Wook Lee, MD, PhD \\ Department of Otorhinolaryngology- \\ Head and Neck Surgery, \\ Chungbuk National University \\ College of Medicine, \\ 776 1sunhwan-ro, Seowon-gu, \\ Cheongju 28644, Korea \\ Tel $+82-43-269-6157$ \\ Fax $+82-43-265-6157$ \\ E-maildwlee@chungbuk.ac.kr
}

Cervical area is not protected by bony structures, so traumatic neck injuries can occur frequently. Emergent surgical exploration is necessary for immediate life threatening signs or symptoms, such as expanding hematoma, hematoma with hemodynamic instability, hemomediastinum, hemothorax or hypovolemic shock. Carotid artery reconstruction may be required in some cases of common carotid or internal carotid artery injury because these injuries could develop fatal or serious complications. We report here a case of common carotid artery injury treated by saphenous vein autograft in an emergent situation

Korean J Otorhinolaryngol-Head Neck Surg 2021;64(5):365-9

Key Words Autologous transplants · Carotid artery injuies - Saphenous vein · Trauma.

\section{서 론}

경부는 밀집된 공간으로, 신경, 근육, 혈관, 호흡기, 소화기, 내분비 여러 중요 구조물들이 있다. 이 공간은 골격으로 보호 되지 않기 때문에 외상으로 인한 손상이 쉽게 일어난다. 특히 관통성 외상은 기도 폐쇄, 혈관 손상으로 인한 대량 출혈, 신 경손상, 뇌경색, 식도 손상 등의 치명적인 합병증이 발생할 수 있으므로, 신속하고 정확한 환자 평가와 처치가 이루어져 야 한다. 이 구조물 중에서도 경동맥은 뇌를 포함한 두경부의 혈액을 공급하며 손상 시에 다량의 출혈 및 뇌의 허혈을 일 으킬 수 있으므로 매우 치명적일 수 있다. 저자들은 날카로운 물체로 인해 경동맥 손상이 의심되는 환자의 응급 수술을 시 행하였다. 수술 중 총경동맥 열상을 확인하여 혈관 외과와

This is an Open Access article distributed under the terms of the Creative Commons Attribution Non-Commercial License (https://creativecommons.org/licenses/by-nc/4.0) which permits unrestricted non-commercial use, distribution, and reproduction in any medium, provided the original work is properly cited.
합동 수술을 시행하였으며, 자가혈관이식을 통하여 치료하였 기에 문헌 고찰과 함께 보고하는 바이다.

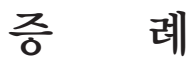

24세 남자 환자가 타인에게 칼로 찔린 후 발생한 좌측 경 부의 열상을 주소로 본원 응급실로 내원하였다. 사고 발생 후 15 분 이내에 본원으로 이송되었으나, 내원 당시 수축기혈압 $80 \mathrm{~mm} \mathrm{Hg}$, 심박수 167회/분으로 대량 출혈로 인한 저혈량성 쇼크(hypovolemic shock) 소견을 보였으며, 의식은 혼미(stupor) 상태로 평가되었다. 이학적 검사상 좌측 측경부에 약 1.5 $\mathrm{cm}$ 의 심경부 자상(stab wound)이 관찰되었으며 해당 부위에 서 대량 출혈도 확인되었다. 이후 혈압 유지를 위해 epinephrine $2 \mathrm{mg}$, norepinephrine $30 \mathrm{mg}$ 과 다량의 수액을 투여하 였지만, 처치 15 분 뒤 수축기혈압 $80 \mathrm{~mm} \mathrm{Hg}$, 이완기혈압 30 $\mathrm{mm} \mathrm{Hg}$, 심박수 134회/분으로 불안정한 상태가 지속되었고 
경부 주요 혈관의 손상이 의심되어 응급 수술을 시행하기로 결정하였다. 불안정한 신체 활력 징후로 인해 수술 전 경부 전산화단층촬영, 혈관조영술 등은 시행하지 못하였다.

수술장에서 전신마취 후 경부 자상에 관해 다시 평가하였 고, 대량 출혈 양상 관찰되어 손가락으로 압박 지혈을 시행하 면서 박리를 시행하였고, 좌측 총경동맥의 가운데를 가로지 르는 약 $2 \mathrm{~cm}$ 의 관통상을 확인하였다. 총경동맥 손상 부위는 완전히 손상되어 일차 봉합(primary repair) 또는 패치 복원 (patch reconstruction)은 불가한 것으로 판단하였다. 상술한 손상 이외 내경정맥, 신경, 식도, 기관의 손상은 관찰되지 않 았고, 우선 좌측 총경동맥의 관통상 부위 근위부와 원위부를 결찰하였다(Fig. 1). 이후 혈관외과와의 협진으로 좌측 대복 재정맥(greater saphenous vein)을 분리하고 총경동맥 손상 부위를 정리한 후 앞서 분리한 대복재정맥 자가이식을 시행 하였다(Figs. 2 and 3). 자가혈관이식 후 총경동맥 근위부, 원 위부 결찰을 제거하였고 연결 부위 및 주변부 출혈이 없음을 확인하고 배액관을 삽입한 뒤 수술을 종료하였다. 총경동맥 결찰에서 자가이식 완료 후 재관류까지 소요된 시간은 약 30 분, 수상시점에서 재관류까지 소요된 시간은 약 90 분이었다. 술후 의식상태는 곧 정상으로 돌아왔으나, 우측 중추성 안면 마비(House-Brackmann grade III)가 확인되었다. 또한 우측 상지의 운동이 grade I으로 저하된 양상이 관찰되었다. 술후 1 일차 시행한 경부 전산화단층촬영과 1 주차에 시행한 경부 혈관조영 전산화단층촬영에서 자가혈관을 이식한 부위의 혈 액 누출은 발견되지 않았다(Fig. 4A), 술후 1일차 우측 팔다

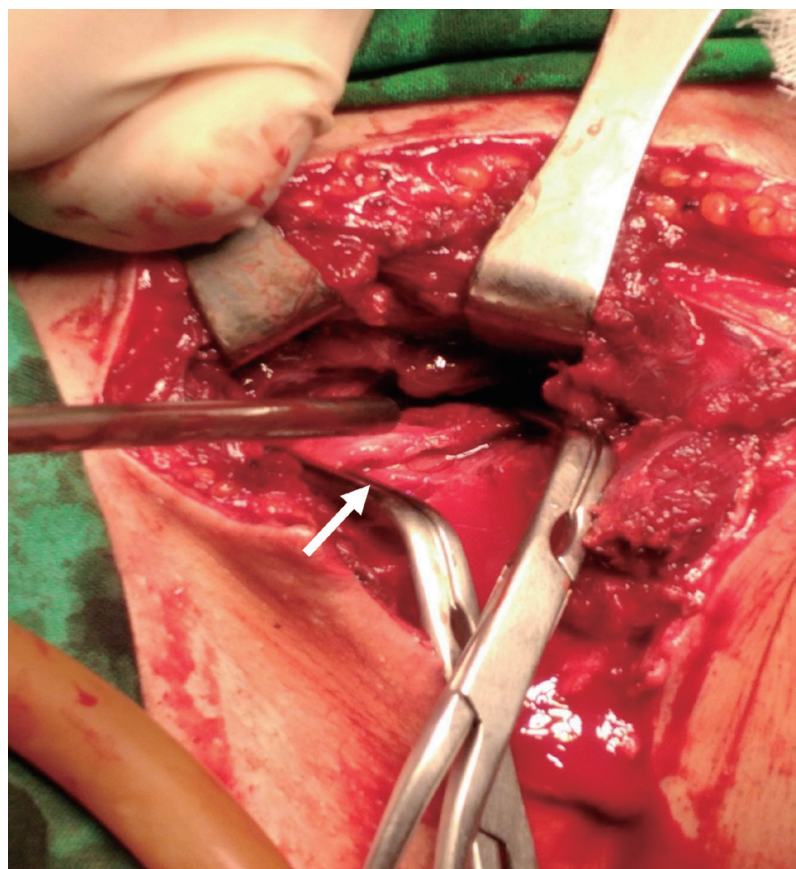

Fig. 1. Exposed carotid laceration area after dissection (arrow).
리에 움직임이 떨어지는 소견이 관찰되어 두부 전산화단층촬 영을 시행하였고 좌측 중뇌동맥 영역(middle cerebral artery territory)에서 경색(infarct) 소견이 관찰되었다(Fig. 4B). 이 후 환자는 재활 치료를 유지했고, 본원에서 재원 14일째에 퇴 원하였다. 퇴원 3개월 후 환자의 우측 중추성 안면마비는 회 복되었고(House-Brackmann grade I), 우측상지 운동기능이 grade III로 좋아진 상태로 clopidogrel $75 \mathrm{mg} / \mathrm{day}$ 를 복용하 며 관찰 지속 중이었고, 재활치료는 타원에서 지속하며 경과 관찰 중이다.

\section{고 찰}

경부는 손상 부위에 따라 Roon과 Christensen이 설명한 것과 같이 3 개 구역으로 나눌 수 있다. 쇄골에서 윤상연골 사이의 부분이 구역 I로 총경동맥의 근위부, 척추동맥, 쇄골 하동맥, 폐첨부, 식도, 기관 및 흥관 등이 위치하며, 이 부위 의 혈관손상 시 근위부로의 접근이 어렵고 처치가 어려워 위

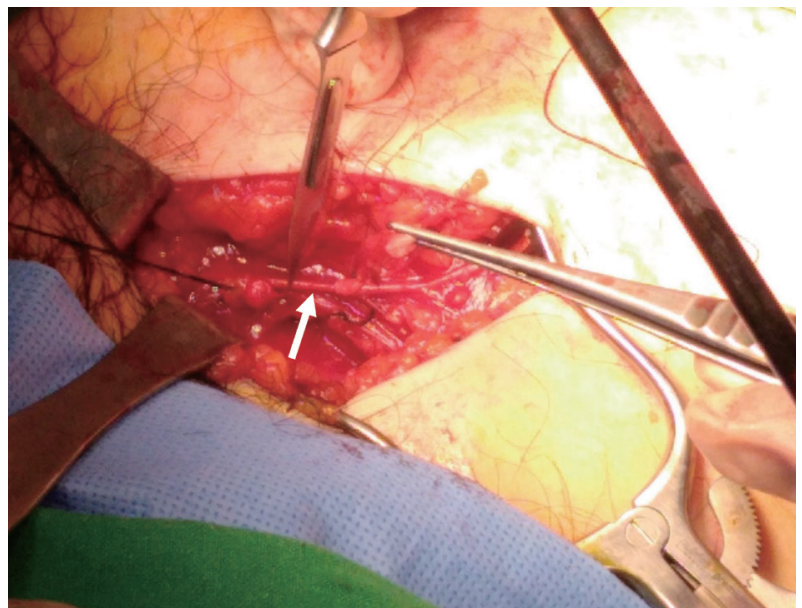

Fig. 2. Harvesting left greater saphenous vein (arrow).

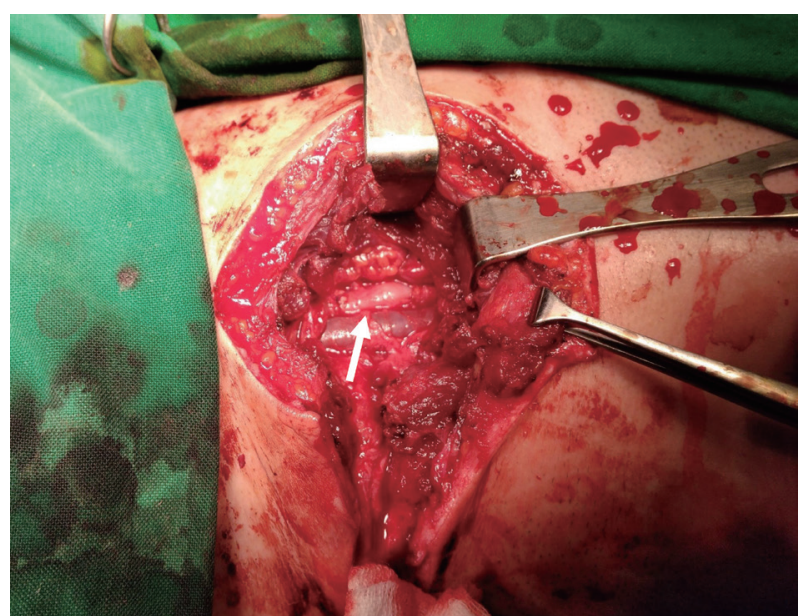

Fig. 3. Interpositioned greater saphenous vein autograft (arrow). 

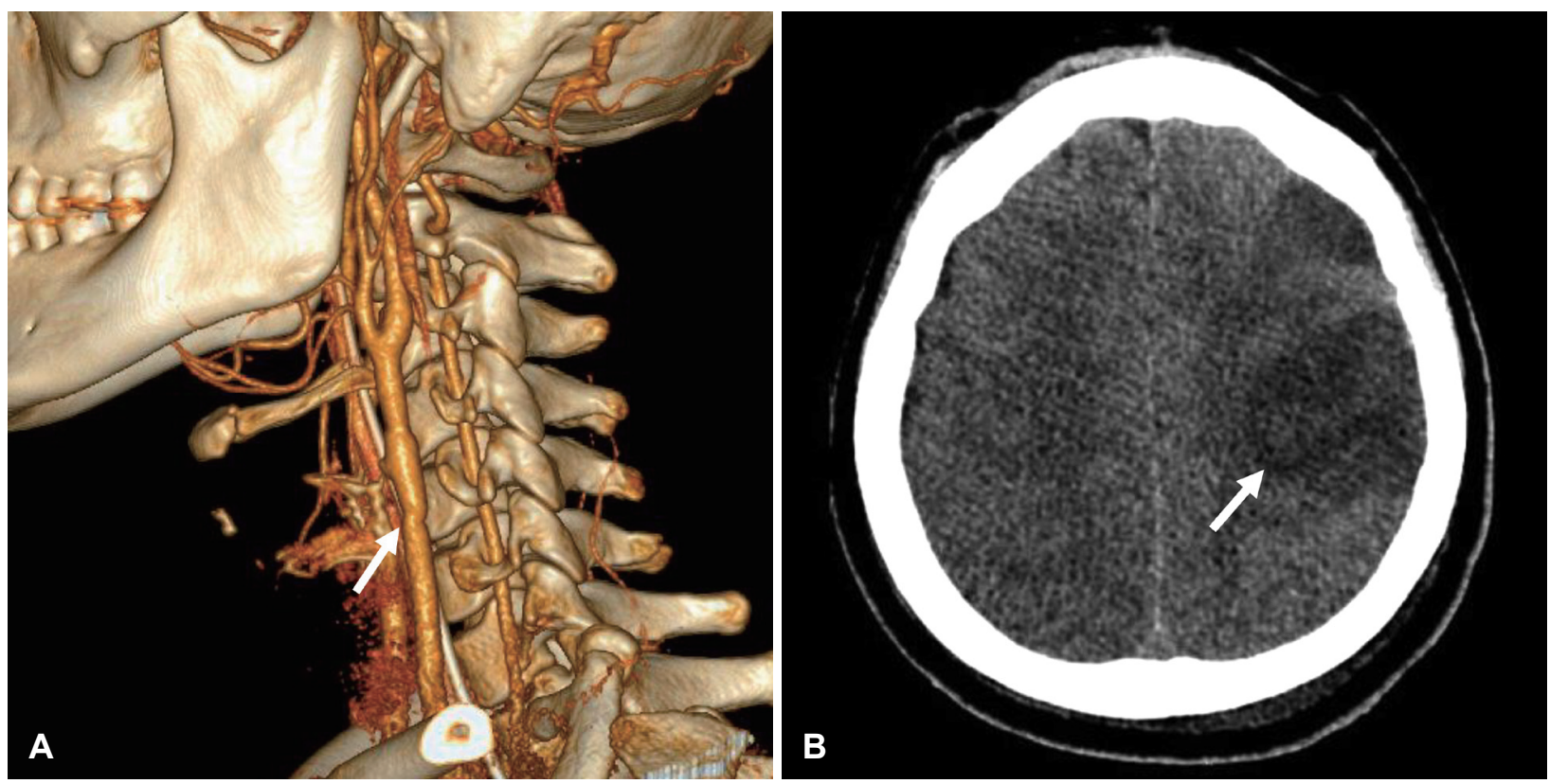

Fig. 4. Postoperative image work up results. Angiogram showing repaired portion of left common carotid artery (arrow). 1 week after operation (A). Axial section of brain CT scan showing middle cranial artery territory infarction (arrow) with hemorrhagic component. 1 day after operation (B).

험 구역으로 알려져 있다.1) 또한 다른 구역과는 다르게 식도 손상의 가능성도 크기 때문에 식도에 대한 평가를 염두에 두 어야 한다. ${ }^{2}$ 구역 I 손상 시 사망률은 비교적 높은 것(12\%) 으로 알려져 있고, 구역 I 손상 시 수술적 탐색(exploration)이 필수적인 것은 아니며 큰 혈관의 손상을 확인하기 위해 혈관 조영술이 권장된다. ${ }^{1)}$ 구역 II는 윤상연골에서 하악각 사이 부 위로 경동맥, 척추동맥, 내경정맥, 후두, 기관, 식도, 미주신경, 되돌이 후두신경, 척수 등을 포함한다. 구역 II는 관통상이 가장 흔히 발생하는 부위(60 75\%)로 수술적 탐색이 반드시 필요한지에 관해서는 논란의 여지가 있다. ${ }^{4)}$ 구역 II 손상에서 수술전 검사 시 쉽게 놓칠 수 있는 것으로는 단독 정맥 손상 (isolated venous injury)와 단독 인두식도 손상(isolated pharyngoeophageal injury)이 있으며, ${ }^{1)}$ 환자의 상태가 안정적이 고 주요 경부 손상의 증상이 없다고 판단될 경우에도 방사선 학적, 내시경적으로 평가한 뒤 입원하여 경과 관찰이 필요하 다고 알려져 있다. 구역 III은 하악각에서 두개골 기저 사이 부분으로 경동맥 원위부, 척추동맥, 이하선, 인두, 척수 및 9 , $10,11,12$ 번 뇌신경 등을 포함한다. 이 구역의 손상 시 뇌신경 의 손상과 다발성의 혈관손상이 발생할 수 있으며, 두개저와 하악골의 위치로 인해 외과적 수술을 통한 지혈이 어렵다. ${ }^{2}$ 따라서 구역 III는 중재적 혈관조영술을 통한 치료를 시행하 기도 한다. ${ }^{2}$

칼, 송곳, 유리 혹은 면도날로 인한 경부 손상은 총상에 비 해 예측 가능한 방향으로 상처가 발생하는 경우가 많으며 여 러 번의 자상(stab wound)에 의한 손상도 겉으로 보이는 상
처는 하나인 경우가 있다. ${ }^{1)}$ 수상기전(공격이 위에서부터 이뤄 졌는지, 아래에서부터 이뤄졌는지 여부 등)에 대한 병력청취 는 의료진에 도움을 줄 수 있으며, 총상에 비해 경부의 자상 은 쇄골하혈관(subclavian vessel)의 손상을 유발하는 경우 가 많다고 알려져 있다. ${ }^{5)}$ 아울러 경부의 자상은 총상에 비해 척수 손상의 빈도가 낮은 것으로 보고된 바 있다. ${ }^{6}$ 환자 상태 가 안정적인 경우에도 추후 가성동맥류(false aneurysm) 또 는 동정맥루(arteriovenous fistula)를 형성할 수 있는 잠재적 인(occult) 손상을 찾기 위한 영상의학 평가가 필요하다.1

경부 관통상은 생명을 위협하는 증상이 있는지 여부가 중 요한데, 생명을 위협하는 증상으로는 대량의 출혈(massive bleeding), 팽창하는 혈종(expanding hematoma), 혈종이 팽 창하지 않지만 혈류역학적 불안정성이 있는 경우(non-expanding hematoma with hemodynamic instability), 혈액종 격동(hemomediastinum), 혈흥(hemothorax), 그리고 저혈량 성 쇼크 등이 있다. ${ }^{1)}$ 이런 경우에는 영상의학적 평가 없이도 즉각적인 수술적 탐색(surgical exploration)이 필요하다. ${ }^{1)}$

본 증례에서는 구역 II에 발생한 경부 관통상으로 epinephrine 투약 이후에도 생체징후가 불안정하고 대량출혈이 진행 중인 상태의 환자로 수술 전 이학적, 신경학적 검사를 충분히 하기 힘들었고, 방사선학적 검사도 시행하지 못한 상 태에서 응급 수술을 결정하게 되었다. 앞서 살펴본 바와 같이 구역 II는 관통상이 가장 흔히 발생하는 부위 $(60 \sim 75 \%)^{4}$ 로 본 증례에서도 구역 II의 외상이 발생하였으며, 구역 II에 포 함된 주요 구조물 가운데 총경동맥 손상이 발견되기는 하였 
으나 식도, 후두, 기간, 미주신경, 되돌이 후두신경, 척수 등 구조물의 손상이 확인되지는 않았다.

경부의 모든 정맥은 출혈을 조절하기 위해 결찰할 수 있지 만 만약 양쪽 내경정맥(internal jugular vein)을 모두 결찰 해야 할 경우에는 한쪽은 복원해주는 것이 좋다. ${ }^{1)}$ 외경동맥 (external carotid artery)은 우회순환(collateral circulation) 이 좋기 때문에 손상시 봉합 결찰(suture ligation)을 이용하 여 쉽게 조절할 수 있다. ${ }^{1)}$ 하지만 총경동맥(common carotid artery) 또는 내경동맥(internal carotid artery)의 결찰은 복 구가 불가능한 혈관손상이 있거나 양쪽 동공이 확장되고 고 정된(bilateral fixed and dilated pupils) 견고한 혼수상태 (profound coma)인 환자인 경우에 시행하게 된다.) Reva 등ㄱ) 은 총경동맥 또는 내경동맥에 발생한 관통상의 수술적 치료 에 있어서 수술적 결찰보다는 복원(repair)이 생존과 신경학 적 결과에 있어서 유리하다고 밝힌 바 있다. 초기 평가시 신경 학적 증상이 없는 경부 동맥 관통상 환자의 경우 뇌졸중이 발생할 확률이 수술적 복원 시 $8 \%$, 결찰 시 $50 \%$, 그리고 수 술하지 않은 경우 $41 \%$ 이며, 사망률은 수술적 복원 혹은 결찰 시 $0 \%$, 수술하지 않은 경우 $18 \%$ 로 보고된 바 있다. ${ }^{8)}$ 경동맥 외상 후 복원까지 소요된 시간에 따른 뇌졸중 발생 빈도와 양상의 상관 관계에 관해 잘 알려진 연구는 없다. 하지만 경 동맥 죽상경화증(carotid atherosclerosis)의 치료로서 행해지 는 경동맥 내막절제술(carotid endcartdectomy) 또는 경동맥 스텐트삽입술(carotid stenting)은 경동맥의 관류가 일시적으 로 중단된다는 점에서 유사한 부분이 있다. 이들 처치와 뇌 졸중의 상관관계에 관한 연구를 참고하면, 처치 전후 시기 (perioperative period)의 경동맥 폐색 시간(occlusion time) 에 따른 뇌허혈(cerebral ischemia)의 빈도에 관한 보고는 부 족하나, ${ }^{9}$ 처치후 30 일째까지 동측 허혈성 뇌졸증(ipsilateral ischemic stroke) 발생 비율이 경동맥 내막절제술에서는 5.14\%, 경동맥 스텐트삽입술에서는 $6.51 \%$ 로 보고된 바 있다. ${ }^{10)} 30$ 일 이후에는 경동맥 내막절제술에서 $2.4 \%$, 경동맥 스텐스삽입술 에서 2.0\%로 보고되었다.11) Eckstein 등리 에 따르면 경동맥 내 막절제술 시행 시 총경동맥 결찰 시간(clamping time)은 평 균 85분(사분범위, interquartile range, 66 105분)이었고 금번 증례에서 수상시점에서 재관류까지 소요된 시간은 약 190분 이었다. 본 증례에서는 수술 전 신경학적 검진을 하기 어려운 상황으로 총경동맥 손상을 확인한 뒤 총경동맥을 즉시 복원 하였으나 재관류까지 소요된 시간이 유사한 처치인 경동맥 내막절제술에 비해 2 배 이상 길었고, 대량 출혈도 동시에 발 생하여 이에 따른 관류 부족으로 좌측 중뇌동맥 영역의 경색 이 발생한 것으로 사료된다. 수술 후 두부 전산화단층촬영에 서 좌측 중뇌동맥 영역 경색 소견이 확인되었는데, 원인 병변
이 명확하고 수술로 관류가 회복되었을 것으로 기대되는 상 황에서 자기공명영상 $(\mathrm{MRI})$ 검사와 같은 추가적인 검사는 반 드시 필요하지 않고, 증상을 관찰하며 추가 검사 여부를 결정 하기로 한 신경과 의견에 따라 자기공명영상검사는 시행하지 않았다.

경동맥 재건 방법으로 이식물 경동맥 우회술(carotid graft bypass)이 이전부터 시행되어 왔으며 이식물(graft)로는 인 공물(prosthetic)과 자가이식물(autogenous)이 대표적이다. ${ }^{13)}$ 복재정맥(saphenous vein)을 이용한 내경동맥 복원은 1959년 Beall 등에 의해 보고된 이후 1970년대 초반 Cornier 등에 의 해 활발히 시행되었고 ${ }^{14}$ Branchereau 등 ${ }^{14}$ 은 정맥을 이용한 경동맥 우회술 212예에서 10년 무신경학적 이상 확률(neurologic event-free population)이 $87 \pm 2.4 \%$ 그리고 10년 복원 개존율(reconstruction patency rate)은 $92.3 \pm 4.5 \%$ 임을 보고 했다. Roddy 등 $^{13)}$ 은 내경동맥 우회술의 재료로 polyteterafluoro ethylene(PTFE)를 사용한 22예와 대복재정맥을 사용 한 22예를 비교한 연구를 시행했고, 무뇌졸중생존율(strokefree survival)과 생존율(survival)에서 통계학적으로 유의미 한 차이가 없음을 밝힌 바 있다. 본 증례에서는 외상으로 발 생한 총경동맥 손상에 대복재정맥을 사용하여 복원을 시행 하였고, 수술 직후 시행한 혈관조영술에서 이상소견 없었으며 수술 후 3 개월째까지 신경학적인 증상 및 협착 소견은 보이지 않았다. 이후 타원 재활치료 중으로 추가적인 평가는 시행하 지 못하였다.

경동맥 우회술의 적응증으로 외상이 언급되기는 하나, 현 재까지 증례는 경동맥 협착에 따른 선택적 수술(elective surgery)이 대부분이다. 특히 자가혈관이식을 통한 응급 경동맥 재건은 전시 혹은 총상이 자주 발생하는 해외에서의 보고는 있으나, 국내에서 보고된 바 없으므로 문헌 고찰과 함께 보 고하는 바이다.

\section{Acknowledgments}

None.

\section{Author Contribution}

Conceptualization: Min Hyuck Kang, Dong Wook Lee. Formal analysis: Dong Wook Lee. Investigation: Min Hyuck Kang. Methodology: Lee Chan Jang. Project administration: Lee Chan Jang. Resources: Dong Wook Lee. Supervision: Dong Wook Lee. Writing_-original draft: Min Hyuck Kang, Young Kang, Hahn Jin Jung. Writing - review \& editing: Min Hyuck Kang, Young Kang, Hahn Jin Jung.

\section{ORCIDs}

Dong Wook Lee https://orcid.org/0000-0002-3333-6083 Young Kang https://orcid.org/0000-0002-0911-8326 


\section{REFERENCES}

1) Flint P, Haughey B, Lund V, Niparko J, Robbins K, Regan JT, et al. Cummings Otolaryngology-Head and Neck Surgery. 6th ed. Amsterdam: Elsevier Health Sciences;2014.

2) Demetriades D, Theodorou D, Cornwell E, Berne TV, Asensio J, Belzberg H, et al. Evaluation of penetrating injuries of the neck: Prospective study of 223 patients. World J Surg 1997;21(1):41-7; discussion 47-8.

3) Rao PM, Bhatti MF, Gaudino J, Ivatury RR, Agarwal N, Nallathambi $\mathrm{MN}$, et al. Penetrating injuries of the neck: Criteria for exploration. J Trauma 1983;23(1):47-9.

4) Obeid FN, Haddad GS, Horst HM, Bivins BA. A critical reappraisal of a mandatory exploration policy for penetrating wounds of the neck. Surg Gynecol Obstet 1985;160(6):517-22.

5) Saletta JD, Folk FA, Freeark RJ. Trauma to the neck region. Surg Clin North Am 1973;53(1):73-86.

6) Ordog GJ, Albin D, Wasserberger J, Schlater TL, Balasubramaniam S. 110 bullet wounds to the neck. J Trauma 1985;25(3):238-46.

7) Reva VA, Pronchenko AA, Samokhvalov IM. Operative management of penetrating carotid artery injuries. Eur J Vasc Endovasc Surg 2011;42(1):16-20.

8) Ramadan F, Rutledge R, Oller D, Howell P, Baker C, Keagy B. Carotid artery trauma: A review of contemporary trauma center experiences. J Vasc Surg 1995;21(1):46-55; discussion 55-6.

9) Li J, Shalabi A, Ji F, Meng L. Monitoring cerebral ischemia during carotid endarterectomy and stenting. J Biomed Res 2017;31(1):11-6.

10) SPACE Collaborative Group, Ringleb PA, Allenberg J, Brückmann $\mathrm{H}$, Eckstein HH, Fraedrich G, et al. 30 day results from the SPACE trial of stent-protected angioplasty versus carotid endarterectomy in symptomatic patients: A randomised non-inferiority trial. Lancet 2006;368(9543):1239-47.

11) Brott TG, Hobson RW 2nd, Howard G, Roubin GS, Clark WM, Brooks W, et al. Stenting versus endarterectomy for treatment of carotid-artery stenosis. N Engl J Med 2010;363(1):11-23.

12) Eckstein HH, Tsantilas $P$, Kühnl A, Haller B, Breitkreuz T, Zimmermann A, et al. Surgical and endovascular treatment of extracranial carotid stenosis. Dtsch Arztebl Int 2017;114(43):72936.

13) Roddy SP, Darling RC 3rd, Ozsvath KJ, Mehta M, Chang BB, Paty PS, et al. Choice of material for internal carotid artery bypass grafting: Vein or prosthetic? Analysis of 44 procedures. Cardiovasc Surg 2002;10(6):540-4.

14) Branchereau A, Pietri P, Magnan PE, Rosset E. Saphenous vein bypass: An alternative to internal carotid reconstruction. Eur J Vasc Endovasc Surg 1996;12(1):26-30. 